\title{
Evaluation of Cotton Genotypes for Drought Tolerance and Their Correlation Study at Seedling Stage
}

\author{
Nasreen Fatima Veesar ${ }^{1}$, Wajid Ali Jatoi ${ }^{1 *}$, Shahnaz Memon $^{2}$, Naila Gandahi ${ }^{1}$, Ghulam Aisha ${ }^{1}$ \\ and Altaf Hussain Solangi ${ }^{1}$ \\ ${ }^{1}$ Department of Plant Breeding and Genetics,Sindh Agriculture University Tandojam, Pakistan \\ ${ }^{2}$ Cotton Research Institute Tandojam Pakistan
}

*Corresponding author: Wajid Ali Jatoi,Department of Plant Breeding and Genetics, Sindh Agriculture University

Tandojam, Pakistan

\section{ARTICLE INFO}

Received: 蔧 July 10, 2020

Published: 幽 July 21, 2020

Citation: Nasreen Fatima Veesar, Wajid Ali Jatoi, Shahnaz Memon, Naila Gandahi, Ghulam Aisha, Altaf Hussain Solangi. Evaluation of Cotton Genotypes for Drought Tolerance and Their Correlation Study at Seedling Stage. Biomed J Sci \& Tech Res 29(1)-2020. BJSTR. MS.ID.004738.

Keywords: Cotton; Screening; Seedling Stage; Correlations

Abbreviations: NLR: Number of Lateral Roots, RWC: Relative Water Content, SC: Stomatal Conductance, WUE: Water Use Efficiency

\section{ABSTRACT}

Droughtstress is considered as themostlimiting factor that reduces crop productivity all over the world. Among the abiotic stresses, drought adversely affects the plant growth and development, consequently the yield. The current research experiment was conducted in RCBD factorial arrangement with two irrigation treatments (nonstress and water stress at seedling stage) in four replications at experimental field, Department of - Plant Breeding and Genetics, Sindh Agriculture University, Tandojam during 2010. Twelve most popular upland cotton cultivars viz. CRIS-134, CRIS-342, Sadori, Chandi, Sindh-1, NIAB-78, CIM-496,CIM-499, CIM-506, CIM-534, BH-160 and Bt cotton (Australian origin) with diverse characters and origin were selected for the study at seedling stage for physiological as well growth parameters under water stress conditions. The growth and physiological traits were comprised of shoot length $(\mathrm{cm})$ root length (cm), Number of Lateral Roots ( NLR) , leaf area (cm2) (LA) , leaf Relative Water Content (RWC),excised leaf water loss (ELWL\%), stomatal density(ST) and Stomatal Conductance (SC) was calculated. The significance of treatments $\mathrm{x}$ genotypes interactions revealed that cotton cultivars performed variably over irrigation regimes. Water stress significantly affected shoot length, root length, number of lateral roots, leaf area, relative water content, excised leaf water loss, stomatal conductance, and stomatal density. Further correlation coefficient revealed that traits were positively and significantly associated except that stomatal conductance was negatively associated with shoot length, root length, and no of lateral roots.

\section{Introduction}

The cotton varieties cultivated in Pakistan encounter various biotic and abiotic stresses. Among the abiotic stresses, water stress poses a severe concern which restricts the cotton productivity in Pakistan and in numerous other parts of the globe [1]. By now, it is well recognized that drought tolerance is a multifaceted phenomenon that adversely affects cotton plant at seedling stage. The developmental stages for cotton plant may be separated into five main growth phases: 1) germination and emergence, 2) seedling establishment, 3) leaf area and canopy development, 4) flowering and boll development and 5) boll maturation. Water stress at beginning developmental phase can deteriorate plant stand due to non-survival of seedlings. Longer duration of drought at seedling stage may become catastrophic for cotton plant, while water stress at peak flowering stage is very critical for seed cotton yield. Water requirement is comparatively higher for cotton plant to retain flowers and young bolls; nonetheless this moisture demand is relatively high at early seedling stages [2]. Due to genetic variability there may be two types of reactions of cultivars for drought increase in root length and decrease in root length.

Root length of crop plants imposed to low soil moisture content of water content sometimes have shown significant increases in root length against those plants which are irrigated adequate water 
without water stress $[3,4]$ and compete for receiving moisture from deeper levels of soil than plants grown under non-stress water conditions [5-8]. Shoot length is also considerably sensitive to water stress, thus cause severe decline in shoot length [4,9]. The Root/ shoot length ratio is regarded as stress adaptive system in response to water shortage conditions; hence it is considered an important indicator for drought stress tolerance. Some physiological attributes like Relative Water Content (RWC) which measures the amount of water retained by the plant in the leaf tissue, thus high RWC in water stress conditions would be preferable to sustain water stress. Higher RWC in leaf tissue has been considered as reliable selection criteria to evolve crop varieties for water shortage environments $[10,11]$

Various morphological, physiological and yield characters are being used to measure drought tolerance when they are correlated with each other. Cotton subjected to water deficient since cotton originates from areas that are often exposed to water-deficit stress [12,13]. Therefore, selection for drought tolerance is a major interest of plant breeders in cotton. A number of different morphological (leaf, stem and root growth parameters) and physiological traits (more than 30 traits) have been suggested as important selection criteria relative to drought tolerance in cotton [14]. However, none of the above physiological traits has so far been consistently correlated positively with drought tolerance [14]. The difficulty in identification of a physiological parameter as a reliable indicator of yield in drought conditions has suggested that yield performance over a range of environments should be used as the main indicator for drought tolerance [15]. Several morphological traits belonging to seedling traits have been reported showing importance in relation to water stress tolerance in cotton [2]. Such traits include taproot mass, density of lateral roots, seedling vigor, rapidity in root development and root/shoot ratio [16]. For drought tolerance, longer taproot was supported by [17]. Two schools of thought exist among the researchers regarding root length under water stress conditions. Some scientists reported that root length of plants subjected to water stress registered significant increase in root length against those plants irrigated with optimum level of water $[3,4]$. On the contrary, some scientists found that root length under drought conditions has decreased seriously [16].

\section{Materials and Methods}

The research was carried out in the experimental area of the Department of Plant Breeding and Genetics at Sindh Agriculture University Tandojam, Pakistan during the years 2010.Twelve most popular upland cotton cultivars viz. CRIS-134, CRIS-342, Sadori, Chandi, Sindh-1, NIAB-78, CIM-496,CIM-499, CIM-506, CIM-534, BH-160 and Btcotton (Australian origin) with diverse characters and origin were studied. The experiment was carried- out in factorial design with two irrigation treatments, non-stress and water stress with four replications. The water regimes were considered as the main factor while varieties as sub-factor. All agricultural inputs and practices like spraying, fertilization, weeding, irrigation and cotton production technology were adopted as recommended for the cotton crop. The data were collected from ten tagged plants in each replication. The seedlings were $t$ part; the plant material was screened at seedling stage against water stress with some developmental and physiological traits $[17,18]$.

Field screening for drought tolerance at seedling stage: Two irrigation regimes i.e. non-stress in which normal irrigations were applied, first after 25 days of sowing and second at 44 days after sowing whereas in water stress treatment, the stress was imposed from sowing till 44 days of the crop growth and development. For developmental and physiological traits, the observations were recorded for shoot length $(\mathrm{cm})$, root length $(\mathrm{cm})$, number of lateral roots, leaf area $\left(\mathrm{cm}^{2}\right)$, leaf relative water content with formula RWC $=[($ Fresh weight-Dry weight $) /($ Turgid weight-Dry weight $)] \mathrm{x}$ 100 , excised leaf water loss (ELWL\%) was calculated by following [19]. with formula E LWL = (Fresh weight -wilted weight $) /$ Dry weight $\mathrm{x} 100$, stomatal conductance $\left(\mathrm{mmolm}^{-2} \mathrm{~s}^{-1}\right)$ was determined in $\mathrm{mmolm}^{-2} \mathrm{~s}^{-1}$ by Prometer-AP4 and stomatal density $\left(\mathrm{mm}^{2}\right)$ by impression method according to technique developed [20]. The soil type of the experimental area was loam and sandy loam in texture. For the cotton experiment area, water content at field capacity varied from 20.3 to $27.6 \%$, and wilting point varied from 7.2 to 9.7 $\%$ on dry weight basis. The dry soil bulk densities ranged from 1.42 to $1.50 \mathrm{~g} \mathrm{~cm}^{3}$ throughout the $1.2 \mathrm{~m}$ deep profile.

\section{Results and Discussion}

Analysis of variance and mean performance of cotton genotypes under water stress conditions at seedling stage. The results revealed that moisture deficit inflicted considerable influence on all the developmental and physiological characters at seedling stage (Table 1). Inconsistent responses of genotypes to water stress were observed because mean squares due to treatment $\times$ genotypes interactions were significant for all the studied characters. Analogous to these results, [21] observed significant influence of water stress on root and shoot length of 80 accessions of cotton examined. The significance of accessions $\times$ treatment interactions revealed differential response of accessions to the two moisture environments. Significant differences for stomatal conductance, water content in leaves and water loss from excised leaves due to drought stress were also noted by [22]. The mean performance of cotton genotypes for various developmental and physiological traits under water stress are discussed here under. 
Table 1: Mean squares from analysis of variance for physiological traits of cotton genotypes grown under non-stress and water stress conditions.

\begin{tabular}{|c|c|c|c|c|c|}
\hline Traits & $\begin{array}{c}\text { Replication } \\
\text { (D.F.=3) }\end{array}$ & $\begin{array}{c}\text { Genotypes (G) } \\
\text { (D.F.=11) }\end{array}$ & $\begin{array}{c}\text { Treatment (T) } \\
\text { (D.F.=1) }\end{array}$ & $\begin{array}{c}\text { G x T } \\
\text { (D.F.=11) }\end{array}$ & Error \\
(D.F.= 69)
\end{tabular}

Note: ${ }^{*}=$ Significant at $1 \%$ of probability level.

Shoot length $(\mathrm{cm})$ : Compared with non-stressed control, drought stress reduced the shoot lengths of cotton genotypes ranging from -4.85 (Sadori) to $-15.00 \mathrm{~cm}$ (Chandi). The maximum drought-induced reduction in shoot length, therefore was noted in Chandi $(-15.00 \mathrm{~cm})$, though this genotype recorded the maximum shoot length under optimum irrigation conditions (Table 2). Cultivars, Chandi, Bt-cotton and BH-160 with maximum declines in shoot length as $-15.00,-13.50$ and $-10.75 \mathrm{~cm}$ respectively were found rather more susceptible to drought stress conditions. In water stress, the shoot lengths of Sadori $(45.15 \mathrm{~cm})$ followed by CRIS-134 (45.10 $\mathrm{cm}$ ) were relatively longer. These genotypes also showed greater tolerance to drought stress due to the fact that the shoot lengths

of Sadori and CRIS-134 genotypes were reduced to only -4.85 and $-5.65 \mathrm{~cm}$ respectively under drought stress conditions. Similar to our findings, [23] found that shoot length of cotton seedlings were decreased due to exposure of drought stress. [24] suggested that shoot growth modifications may influence the root growth and development, thus may interfere with the cotton susceptibility to water stress. Response of cotton genotypes to water stress involves osmotic adjustment, elasticity to photochemical apparatus and stomatal conductance; hence the nature of shoot and root growth and development determine responses of genotypes to water stress $[24,25]$ stated that water deficiency at initial vegetative stage has substantially reduced the shoot and root dry-matter in cotton plant.

Table 2: Mean performance for shoot length and root length of cotton genotypes grown under non-stress and water stress conditions.

\begin{tabular}{|c|c|c|c|c|c|c|}
\hline \multirow{2}{*}{ Genotypes } & \multicolumn{2}{|c|}{ Shoot length (cm) } & \multirow{2}{*}{ R.D* } & \multicolumn{2}{|c|}{ Root length $(\mathrm{cm})$} & \multirow{2}{*}{ R.D* } \\
\hline & Non-stress & Water stress & & Non-stress & Water stress & \\
\hline CRIS-134 & 50.75 & 45.1 & -5.65 & 23.5 & 28 & 4.5 \\
\hline CRIS-342 & 42.25 & 35.33 & -6.93 & 18.63 & 14 & -4.63 \\
\hline Sadori & 50 & 45.15 & -4.85 & 21.75 & 24.75 & 3 \\
\hline Chandi & 51.5 & 36.5 & -15 & 16.75 & 14.25 & -2.5 \\
\hline Sindh-1 & 49.5 & 43.5 & -6 & 20.63 & 24 & 3.38 \\
\hline NIAB-78 & 46.25 & 36.75 & -9.5 & 15 & 12.25 & -2.75 \\
\hline CIM-496 & 51 & 45 & -6 & 19.5 & 22.75 & 3.25 \\
\hline CIM-499 & 41 & 32.5 & -8.5 & 17.25 & 12.5 & -4.75 \\
\hline CIM-506 & 47.5 & 41.5 & -6 & 21.75 & 25.5 & 3.75 \\
\hline CIM-534 & 48.25 & 41.5 & -6.75 & 21.25 & 26 & 4.75 \\
\hline BH-160 & 45.75 & 35 & -10.75 & 14 & 13 & -1 \\
\hline Bt (Aust) & 45.5 & 32 & -13.5 & 13.25 & 12.5 & -0.75 \\
\hline Mean & 47.44 & 39.15 & -8.29 & 18.6 & 19.13 & 0.25 \\
\hline LSD(5\%) Genotypes (G) & \multicolumn{2}{|c|}{1.65} & & \multicolumn{2}{|c|}{0.99} & \\
\hline Treatment (T) & \multicolumn{2}{|c|}{0.67} & & \multicolumn{2}{|c|}{0.40} & \\
\hline $\mathrm{G} \times \mathrm{T}$ & \multicolumn{2}{|c|}{2.33} & & \multicolumn{2}{|c|}{1.41} & \\
\hline
\end{tabular}

Note:*RD = Relative difference between non-stress and water stress treatments. 
Root length (cm): It is by now well understood that, all the root parameters are essential for water stress tolerance. A number of researchers have observed the prospective function of roots under moisture-deficit conditions [26]. The cotton genotypes evaluated under water stress responded differentially to drought stress. However, water stress reduced the root length of varieties CIM-499, CRIS-342, NIAB-78, Chandi, BH-160 and Bt-cotton by $-4.75,-4.63$, $-2.75,-2.50,-1.00$, and $-0.75 \mathrm{~cm}$, respectively, yet cultivars CRIS342 and CIM-499 were found more susceptible to drought stress because these cultivars recorded higher reductions in root length attributable to moisture stress. Contrary to above findings, the root length of varieties like CIM-534, CRIS-134, CIM-506, Sindh-1, CIM496 and Sadori were increased rather declined by 4.75, 4.50, 3.75, $3.38,3.25$ and 3.00 respectively under water stress indicating their drought tolerance (Table 2). In consonance with our findings, [27, 28] observed that moderate water stress at seedling stage caused increase in root length while moisture stress at reproductive stage or longer period have condensed the root development. In another study, [28] pointed-out that genetically modified cottons were more tolerant to water stress because of good rooting system against wild type cotton. Profuse and deeper root systems are often desirable characteristics for drought adaptation. Deep root system also imparts drought resistance in many crop plants. In cotton, diploid species have high degree of drought tolerance by virtue of their deep root system [29,30]. Generally deep-rooted plants exhibit greater drought tolerance than shallow rooted genotypes. Therefore, first irrigation is usually delayed in cotton up to 40 days, so that roots may become longer in natural conditions for search of deep soil moisture.

Number of lateral roots: The important characteristic of roots in drought-tolerant plants is the presence of young lateral roots which are also called as focal sites of water uptake [31]. Water stress induced significant variations in lateral roots of cotton seedlings (Figure 1), yet the genotypes also responded variably under water stress conditions. Exposure of water stress reduced the number of lateral roots in cultivars NIAB-78, CIM-499, Bt-cotton, Chandi, CRIS-342 and BH-160 and by $-3.00,-3.00,-3.00,-2.75-1.75$, and -1.25 roots respectively (Table 3 ). Inversely, the number of lateral roots of varieties like Sindh-1, CRIS-134, Sadori, CIM-534, CIM499 and CIM-506 were increased by 5.50, 5.00, 4.50, 4.00, 3.75, and 3.50 respectively revealing their water stress tolerance. Under drought stress as well as control conditions, CRIS-134, Sadori and Sindh-1 recorded a greater number of lateral roots than rest of the genotypes (Table 3). Analogous to present results, [32]. found two drought tolerant cotton genotypes while [30]. observed six cotton genotypes which produced higher number of lateral roots indicating their drought tolerance while [33]. observed that severe water stress reduced the root proliferation.

Table 3: Mean performance for number of lateral roots and leaf area of cotton genotypes grown under non-stress and water stress conditions.

\begin{tabular}{|c|c|c|c|c|c|c|}
\hline \multirow{2}{*}{ Genotypes } & \multicolumn{2}{|c|}{ No. of lateral Roots } & \multirow{2}{*}{ R.D* } & \multicolumn{2}{|c|}{ Leaf area $\left(\mathrm{cm}^{-2}\right)$} & \multirow{2}{*}{ R.D* } \\
\hline & Non-stress & Water stress & & Non-stress & Water stress & \\
\hline CRIS-134 & 15.5 & 20.5 & 5 & 116 & 107.25 & -8.75 \\
\hline CRIS-342 & 14 & 12.25 & -1.75 & 103 & 92 & -11 \\
\hline Sadori & 16 & 20.5 & 4.5 & 107 & 98 & -9 \\
\hline Chandi & 13 & 10.25 & -2.75 & 109 & 90.25 & -18.75 \\
\hline Sindh-1 & 15 & 20.5 & 5.5 & 106.75 & 100.75 & -6 \\
\hline NIAB-78 & 14 & 11 & -3 & 107.5 & 92.25 & -15.25 \\
\hline CIM-496 & 15 & 18.75 & 3.75 & 130.75 & 124.25 & -6.5 \\
\hline CIM-499 & 15.5 & 12.5 & -3 & 125.75 & 100.75 & -25 \\
\hline CIM-506 & 15.5 & 19 & 3.5 & 121.25 & 111.25 & -10 \\
\hline CIM-534 & 14.75 & 18.75 & 4 & 117.25 & 110.75 & -6.5 \\
\hline BH-160 & 13.75 & 12.5 & -1.25 & 119.5 & 90.75 & -28.75 \\
\hline Bt (Aust) & 12 & 9 & -3 & 86 & 65 & -21 \\
\hline Mean & 14.5 & 15.46 & 0.96 & 112.48 & 98.6 & -13.88 \\
\hline LSD (5\%) Genotypes (G) & \multicolumn{2}{|c|}{0.88} & \multirow{3}{*}{0.96} & \multicolumn{2}{|c|}{1.06} & \multirow{3}{*}{-13.88} \\
\hline Treatment $(\mathrm{T})$ & \multicolumn{2}{|c|}{0.36} & & \multicolumn{2}{|c|}{0.43} & \\
\hline Gx T & \multicolumn{2}{|c|}{1.25} & & \multicolumn{2}{|c|}{1.49} & \\
\hline
\end{tabular}

Note: *RD = Relative difference between non-stress and water stress treatments. 


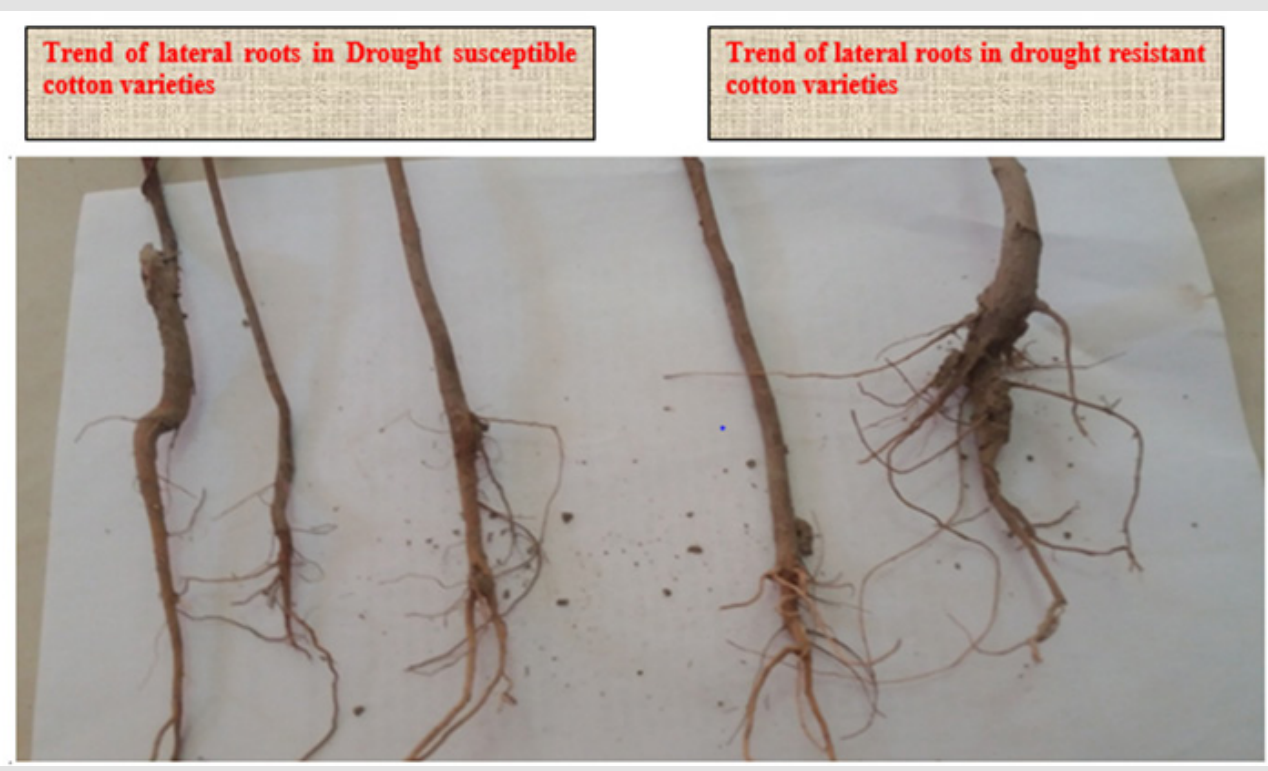

Figure 1: Trend of lateral root architecture in drought resistant and drought susceptible cotton varieties.

Leaf area $\left(\mathrm{cm}^{2}\right)$ : Leaf area is one of the main determinants of crop yield as it regulates plant water balance through its influence on transpiration [34]. Results regarding leaf area of cotton genotypes showed significant variations under the influence of drought stress, yet some varieties showed higher reductions in leaf area than the others due to water stress (Table 3). Drought stress generally reduced the leaf area of all the twelve cotton genotypes evaluated with the range of -6.00 to $-28.75 \mathrm{~cm}^{2}$. Under water stress, the maximum reductions in leaf area however was recorded in $\mathrm{BH}$ $160\left(-28.75 \mathrm{~cm}^{2}\right)$ closely followed by CIM-499 $\left(-25.00 \mathrm{~cm}^{2}\right)$ and Btcotton $\left(-21.00 \mathrm{~cm}^{2}\right)$ revealing their vulnerability to water stress. While other groups of cultivars like CIM-496, CIM-534, and Sindh-1 showed tolerance to drought stress due to reason that leaf area of these genotypes was less affected by stress and reduction was noted as $-6.50,6.50$, and $-6.00 \mathrm{~cm}^{2}$ respectively. [35] in his study observed that water stress resulted in reductions of all plant organs including total plant weight. However, he stated that declines in the leaf area below the optimum leaf area index will decrease crop growth rate and total photosynthesis per plant which ultimately will decrease the yield. Under well water condition, leaf area index increases along with growth rate, but it decreases in water deficit condition due to leaf area adjustment process. [36] conducted a pot experiment in green house on two cotton varieties and observed $24 \%$ and $29 \%$ decrease in leaf area of two genotypes respectively in drought-stressed plants. [37] noted the consequence of drought stress on leaf area at various reproductive stages of cotton and concluded that drought stress decreased leaf area in all the stages of the crop except maturity.

Relative water content (RWC \%): High RWC\% under drought stress conditions may be preferable to maintain water balance, thus higher RWC\% may be adopted as good criteria to breed plants for water stress tolerance [11]. Moisture stress tolerance can be achieved through the capability of plants to minimize evaporation via stomatal shutting and modifications in leaf phenotype [38]. In present study, drought stress caused considerable declines in RWC\% of the genotypes under screening and the reduction ranged from -26.50 to $-48.50 \%$ (Table 4). The maximum reductions in RWC\% due to drought stress was recorded in varieties CIM-499 $(-48.50 \%)$ closely followed by NIAB-78 $(-47.50 \%)$ and Bt-cotton $(-45.50 \%)$. On an average, decline of $-36.25 \%$ was recorded due to water stress. However, other cultivars such as CIM-506, CRIS-134 and CIM-534 showed tolerance to drought stress by showing less declines in RWC\% and these genotypes recorded reductions of $-26.750,-26.50$ and $-28.25 \%$ due to water stress. Moisture stress caused substantial decline in yield, growth and leaves water content as reported by [22]. However, some varieties recorded higher growth and yield and also sustained higher leaf water content and more photosynthesis. Leaf relative water content was observed as $69 \%$ and $45 \%$ in transgenic and wild-type plants, respectively at 10-day drought stress. Similarly, transgenic plants showed better performance due to stress responsive genes for photosynthesis, stomatal conductance, transpiration, and osmotic potential as compared to wild type [39].

Excised leaf water loss (ELWL\%): The cultivars possessing ability of low rate excised leaf water loss how drought resistance. Therefore, ELWL\% was recommended as best measure for tolerance to water stresses [11]. Variable response of cotton genotypes was observed for ELWL\% under water stress at seedling stage. Drought stress increased the excised leaf water loss of all the cotton genotypes in the range of -14.50 to $-27.50 \%$. The maximum 
reduction in ELWL\% nevertheless was recorded in varieties Btcotton followed by NIAB-78 and BH-160 (Table 4). Some genotypes like CIM-496, CRIS-134 and CIM-534 showed lower ELWL\% under drought stress, the relative ELWL\% of these genotypes was with
$-13.00,-14.50$ and $-17.50 \%$, hence demonstrated their stress tolerance. Analogous to our findings, [39] also observed negative effects of water stress on excised leaf water loss in water shortage conditions.

Table 4: Mean performance for relative water content and excised leaf water loss of cotton genotypes grown under non-stress and water stress conditions.

\begin{tabular}{|c|c|c|c|c|c|c|}
\hline \multirow{2}{*}{ Genotypes } & \multicolumn{2}{|c|}{ RWC (\%) } & \multirow[t]{2}{*}{ R.D* } & \multicolumn{2}{|c|}{ Excised leaf water loss (\%) } & \multirow[b]{2}{*}{ R.D* } \\
\hline & Non-stress & Water stress & & Non-stress & Water stress & \\
\hline CRIS-134 & 91.5 & 65 & -26.5 & 81.5 & 67 & -14.5 \\
\hline CRIS-342 & 87.25 & 52.5 & -34.75 & 85.25 & 66 & -19.25 \\
\hline Sadori & 92 & 61.25 & -30.75 & 87.75 & 70 & -17.75 \\
\hline Chandi & 90.5 & 49 & -41.5 & 79.5 & 60 & -19.5 \\
\hline Sindh-1 & 89.5 & 58.25 & -31.25 & 85 & 67.25 & -17.75 \\
\hline NIAB-78 & 88 & 40.5 & -47.5 & 78 & 51.75 & -26.25 \\
\hline CIM-496 & 98 & 66 & -32 & 84.5 & 71.5 & -13 \\
\hline CIM-499 & 90.5 & 42 & -48.5 & 79 & 58.5 & -20.5 \\
\hline CIM-506 & 87.5 & 60.75 & -26.75 & 76.75 & 58 & -18.75 \\
\hline CIM-534 & 84.75 & 56.5 & -28.25 & 80.75 & 63.25 & -17.5 \\
\hline BH-160 & 82.75 & 41 & -41.75 & 86.5 & 63 & -23.5 \\
\hline Bt (Aust) & 80.5 & 35 & -45.5 & 76.5 & 49 & -27.5 \\
\hline Mean & 88.56 & 52.31 & -36.25 & 81.75 & 62.1 & -19.65 \\
\hline LSD $(5 \%)$ Genotypes (G) & \multicolumn{2}{|c|}{0.95} & & \multicolumn{2}{|c|}{3.02} & \\
\hline Treatment (T) & \multicolumn{2}{|c|}{0.38} & -36.25 & \multicolumn{2}{|c|}{1.22} & 19.65 \\
\hline $\mathrm{G} \times \mathrm{T}$ & \multicolumn{2}{|c|}{1.34} & & \multicolumn{2}{|c|}{4.24} & \\
\hline
\end{tabular}

Note: ${ }^{*} \mathrm{RD}=$ Relative difference between non-stress and water stress treatments.

Stomatal conductance $\left(\mathrm{mmolm}^{-2} \mathrm{~s}^{-1}\right)$ : Stomatal conductance of cotton genotypes was significantly altered under the influence of drought stress. Likewise, the cotton genotypes responded differentially to drought stress conditions. Under drought stress, cotton genotypes decreased the stomatal conductance varying from -55.50 to $-101.50 \mathrm{mmolm}^{-2} \mathrm{~s}^{-1}$. In drought stress, the maximum drop in stomatal conductance was recorded in Sadori $(-101.50$ mmolm $\left.{ }^{-2} \mathrm{~s}^{-1}\right)$ distantly followed by CIM-506 (-90.50 mmolm $\left.\mathrm{m}^{-1}\right)$, hence indicating their less vulnerability in water stress conditions (Table 5). Nonetheless, Chandi, NIAB-78 and CIM-499 genotypes recorded less declines in stomatal conductance under drought stress showing their higher susceptibility to water stress.

Drought stress significantly affected stomatal conductance which declined by $41.52 \%$ across the 182 genotypes from 39.53 $\mathrm{mmolm}^{-2} \mathrm{~s}^{-1}$ in the control to $23.12 \mathrm{mmolm}^{-2} \mathrm{~s}^{-1}$ under drought stress [40]. Since water use efficiency is higher in genotypes which are characterized by stomatal conductance, often resulting from a lower water status, but such genotypes disadvantageously extract more water from the soil [41,42]. Whilst maintaining higher stomatal conductance, can produce higher yields. Conversely, under conditions of limited soil moisture, low Water Use Efficiency
(WUE) resulting from excessive evapo-transpiration will not allow sustained accumulation of dry matter and its partitioning to reproductive organs $[43,44]$ found that the water stress lowered the stomatal conductance, thus some varieties were less affected by water stress and maintained their stomatal conductance.

Stomatal density $\left(\mathrm{mm}^{2}\right)$ : Decline of moisture via leaves is an important occurrence in cotton plants in water stress conditions [45]. Cotton genotypes under present study exhibited significant variations in stomatal density of under the influence of drought stress. Likewise, the cotton genotypes responded changeably to drought stress (Figure 2), some being less affected than the others (Figure 3). On an average, the stomata numbers declined by $-16.85 \mathrm{~mm}^{2}$. Against non-stressed control, drought stress decreased the stomatal density of cotton genotypes in the range of -10.00 to $-23.00 \mathrm{~mm}^{2}$. Among the genotypes, the maximum drought-induced reductions in stomatal density were recorded in CIM-506 followed by CIM-534, Sadori and CRIS-134 as compared to other cultivars screened (Table 5 \& Figure 3). These cultivars performed better since maximum reduction in stomata helped them to sustain water stress and retain more water with less evapo-transpiration from leaves. 
Table 5: Mean performance for stomatal conductance and stomatal density of cotton genotypes grown under non-stress and water stress conditions.

\begin{tabular}{|c|c|c|c|c|c|c|}
\hline \multirow{2}{*}{ Genotypes } & \multicolumn{2}{|c|}{ Stomatal conductance $\left(\mathrm{mmols}-2 \mathrm{~s}^{-1}\right)$} & \multirow{2}{*}{ R.D* } & \multicolumn{2}{|c|}{ Stomatal density $\left(\mathrm{mm}^{2}\right)$} & \multirow{2}{*}{ R.D* } \\
\hline & Non-stress & Water stress & & Non-stress & Water stress & \\
\hline CRIS-134 & 210 & 132.75 & 77.25 & 40 & 30 & 10.00 \\
\hline CRIS-342 & 316.25 & 245 & 71.25 & 46.25 & 26.5 & 19.75 \\
\hline Sadori & 242.25 & 140.75 & 101.5 & 41 & 28 & 13.00 \\
\hline Chandi & 340 & 283.75 & 56.25 & 46 & 24.75 & 21.25 \\
\hline Sindh-1 & 230.5 & 146.5 & 84 & 40 & 26.75 & 13.25 \\
\hline NIAB-78 & 343 & 286 & 57 & 45 & 28 & 17.00 \\
\hline CIM-496 & 218.75 & 145.5 & 73.25 & 40 & 24.25 & 15.75 \\
\hline CIM-499 & 380 & 289.5 & 90.5 & 42 & 24.25 & 17.75 \\
\hline CIM-506 & 216 & 130 & 86 & 46 & 30.25 & 15.75 \\
\hline CIM-534 & 242.5 & 150.5 & 92 & 40.75 & 25 & 15.75 \\
\hline BH-160 & 284.5 & 200.5 & 84 & 48 & 28 & 20.00 \\
\hline Bt (Aust) & 247.25 & 191.75 & 55.5 & 49 & 26 & 23.00 \\
\hline Mean & 272.58 & 195.21 & 77.38 & 43.67 & 26.81 & 16.85 \\
\hline LSD (5\%) Genotypes (G) & \multicolumn{2}{|c|}{4.66} & & \multicolumn{2}{|c|}{0.6} & \\
\hline Treatment (T) & \multicolumn{2}{|c|}{1.9} & & \multicolumn{2}{|c|}{0.24} & \\
\hline $\mathrm{G} \times \mathrm{T}$ & \multicolumn{2}{|c|}{6.60} & & \multicolumn{2}{|c|}{0.84} & \\
\hline
\end{tabular}

Note: ${ }^{*} \mathrm{RD}=$ Relative difference between non-stress and water stress treatments.

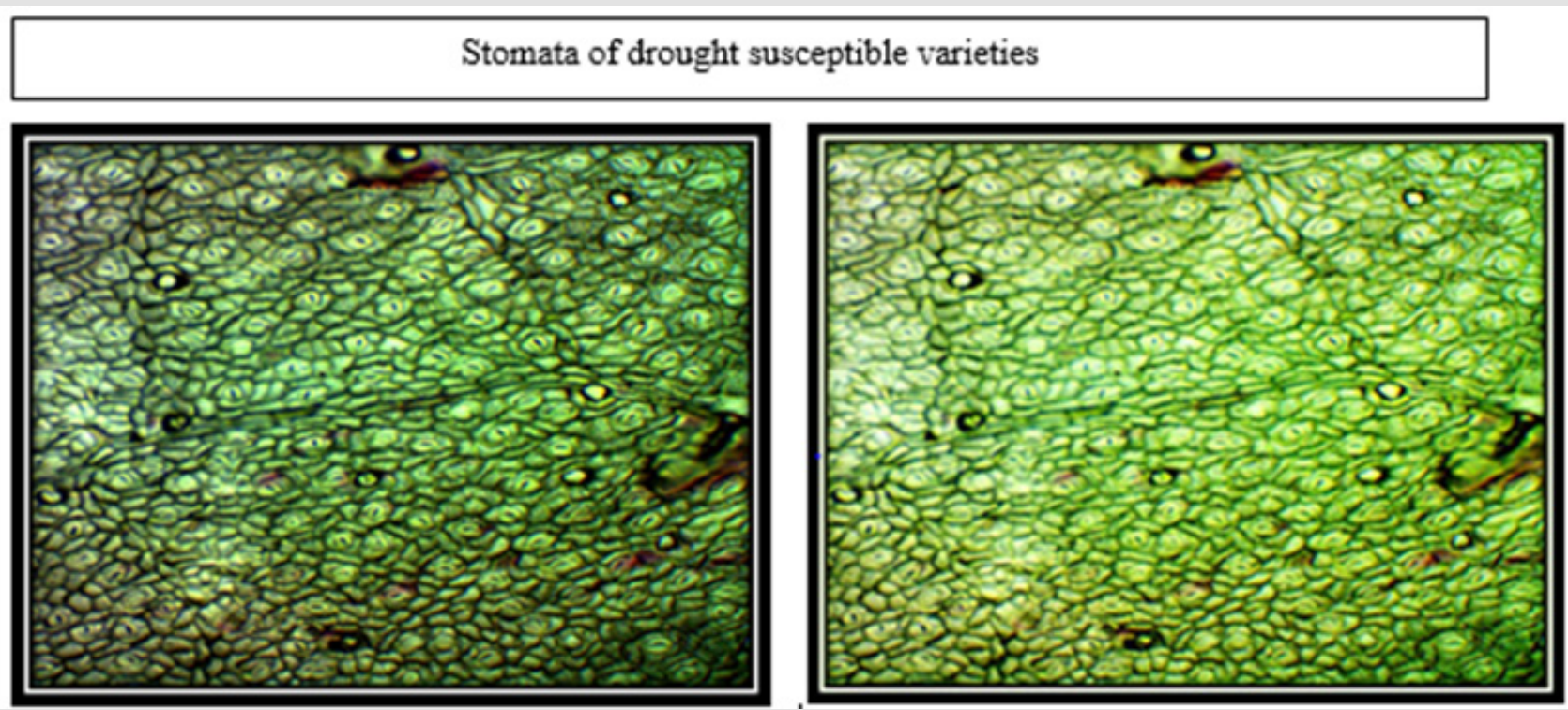

Figure 2: Presentation of cotton stomata of drought susceptible varieties. 


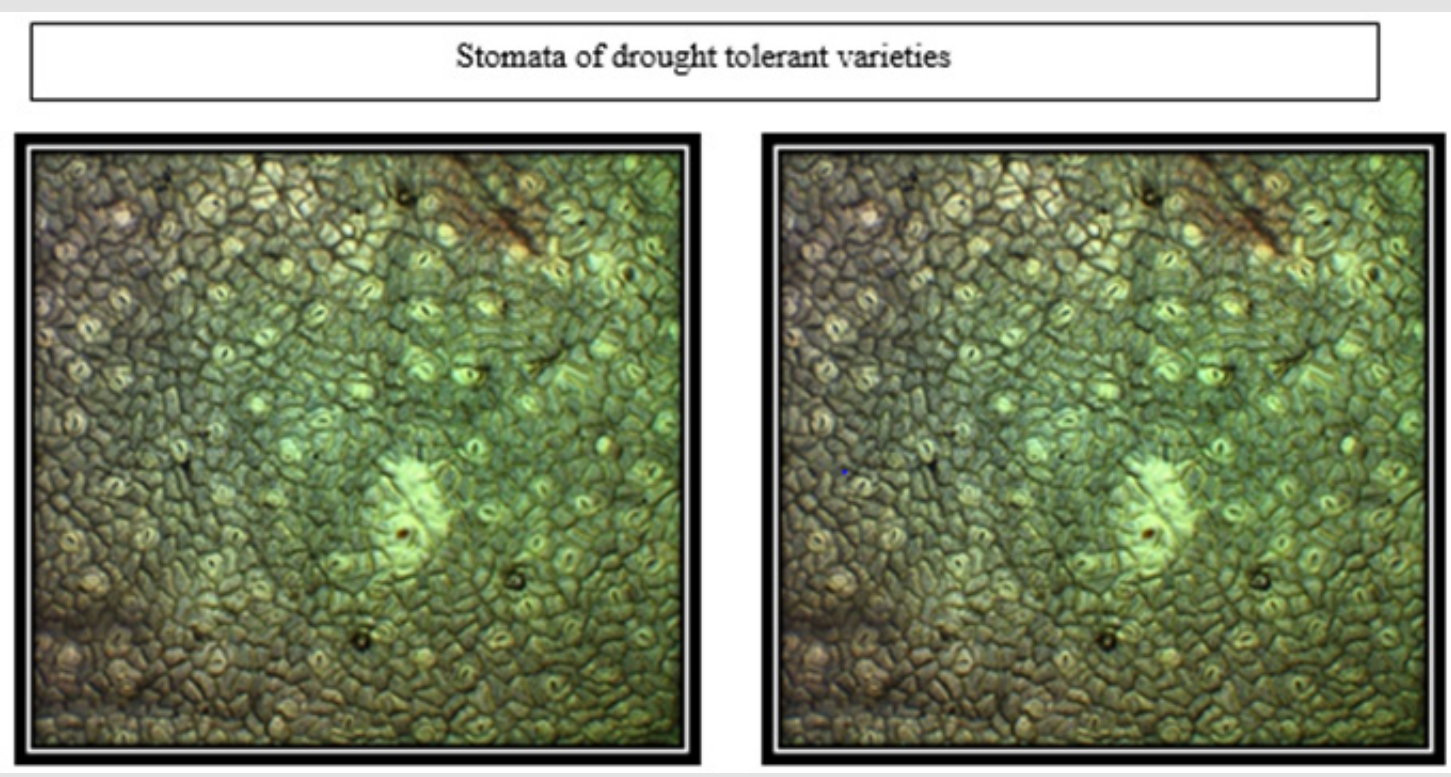

Figure 3: Presentation of cotton stomata of drought tolerant varieties.

[46] noted that stomatal density increased as water stress increased, while the maximum stomatal aperture reduced only in the severe stressed plants. [47] observed a reduction of $14.24 \%$ in stomatal density in low moisture. The time of the maximum stomatal aperture was delayed in the mild and severe stressed plants. When severe stress occurred, the stomata were kept open until the transpiration decreased to nearly zero, suggesting that the stomata might not be the main factor in adjusting transpiration in cotton. Different plant traits are reported to enhance water stress tolerance which include chunky leaves, thicker palisade cells, stout epidermis, more hairs on plan parts, thicker parenchyma cells, smaller stomata, more palisade cells against to spongy cells [4850] stated that stomata hole very important functions of plant like maintaining cellular function and producing energy. Stomata conductance may also be important gauge for measuring drought tolerance in cotton because of negative association of drought tolerance with stomata conductance.

\section{Correlations (R) Between Development and}

\section{Physiological Traits}

There was a significant positive association of shoot length with root length, number of lateral roots, leaf area, relative water content and stomatal density (Table 6). These results indicated that when shoot length increases, it correspondingly increases the plant roots, smaller lateral roots, leaf area, RWC and stomatal count per unit area. Root length showed significant positive associations with number of lateral roots, leaf area and relative water content, while significantly negative association of root length was observed with stomatal conductance and number of lateral roots. The negative correlations of root length with stomatal conductance and lateral roots revealed that as the length of roots increase, it causes more evapo-transpiration. Leaf area showed significant and positive relationship with water content in leaves. The relationship of stomatal density with leaf area, water content in leaves, water loss from excised leaves, and stomatal conductance was also significant and positive. The relationships of leaf area with characters related to evapo-transpiration are well documented. It has been stated that RWC was considered as impotent parameter for determining water status in plant leaves. The preference of RWC to be important illustration of plant water status due to genetic variation also hold true because of close alliance between relative water content and yield in water stress Available reports revealed that drought tolerant species reduce the water loss by reducing the leaf area and also restricting stomatal opening.

Table 6: correlation co-efficient between developmental and physiological trait of cotton genotypes under water stress condition.

\begin{tabular}{|c|c|c|c|c|c|c|c|}
\hline Traits & SL & RL & NLR & LA & RWC & ELWL & SC \\
\hline RL & $0.486^{* *}$ & & & & & \\
\hline NLR & $0.400^{* *}$ & $0.872^{* *}$ & & & & \\
\hline LA & $0.631^{* *}$ & $0.476^{* *}$ & $0.487^{* *}$ & & & \\
\hline RWC & $0.849^{* *}$ & $0.273^{* *}$ & 0.189 & $0.682^{* *}$ & & \\
\hline ELWL & $0.774^{* *}$ & 0.196 & 0.16 & $0.606^{* *}$ & $0.914^{* *}$ & \\
\hline SC & -0.02 & $-0.640^{* *}$ & $-0.597^{* *}$ & 0.062 & $0.336^{* *}$ & $0.314^{* *}$ & \\
\hline SD & $0.639^{* *}$ & -0.098 & -0.148 & $0.382^{* *}$ & $0.855^{* *}$ & $0.790^{* *}$ & $0.537^{* *}$ \\
\hline
\end{tabular}




\section{Data Availability Statement}

The data mentioned in the manuscript are available at any time for the guidance of researchers and scientists.

\section{References}

1. Saranga Y, Menz M, Jiang CX, Robert JW, Yakir D, et al. (2001) Genomic dissection of genotype $\mathrm{x}$ environment interactions conferring adaptation of cotton to arid conditions. Genome Res 11: 1988-1995.

2. Riaz M, Farooq J, Sakhawat G,Mahmood A,Yaseen M (2013) Genotypic variability for root/shoot parameters under water stress in some advanced lines of cotton (Gossypiumhirsutum L). Genet Mol Res 12(1): 552-561.

3. Chaitante D, DA Iorio, Maiuro L, Scippa SG (2000) Effect of water stress on root meristems in woody and herbaceous plants during the first stage of development. Function and Physiology pp.245-258.

4. Abdalla MM, NH El Khoshiban (2007) The influence of water stress on growth, relative water content, photosynthetic pigments, some metabolic and hormonal contents of two Triticum aestivum cultivars. J Appl Sci Res 3(12): 2062-2074.

5. Kamara AY, Menkir A, Babu-Apraku B, Ibikunle O (2003) The influence of drought stress on growth, yield and yield components of stressed maize genotypes. J Agric Sci 141(101): 43-50.

6. Rizza F, FW Badeck, Cattivelli L, Lidestri O(2004) Use of a water stress index to identify barley genotypes adapted to rainfed and irrigated conditions. Crop Sci 44: 2127-2137.

7. Moinuddin, RA, A Fisher, KD Sayre and MP Reynolds (2005) Osmotic adjustment in wheat in relation to grain yield under water deficit environments Agron J 97: 1062-1071.

8. Hufstetler VE, Boerma TEJ Carter, HJ Earl (2007) Genotypic variation for three physiological traits affecting drought tolerance in soybean. Crop Sci 47: 25-35.

9. SchuzendubelA,Nikolova P, Rudolf C, PolleA (2002) Cadmium and $\mathrm{H}_{2} \mathrm{O}_{2}$-induced oxidative stress in populous $\mathrm{x}$ canescens roots Plant PhysiolBiochem 40: 577-584.

10. Malik TA, Wright D, Virk DH (1999) Inheritance of net photosynthesis and transpiration efficiency in spring wheat, Triticum aestivum $\mathrm{L}$, under drought. Plant Breed 118(1): 93-95.

11. Rahman S, Shaheen MS, Rahman M, Malik TA (2000) Evaluation of excised leaf water loss and relative water content as screening techniques for breeding drought resistant wheat Pak. J Biol Sci 3: 663-665.

12. Pettigrew WT, Meredith WR (1994) Leaf gas exchange parameters vary among cotton genotypes. Crop Sci 34(3): 700-705.

13. Lacape MJ, Wery J, DJM Annerosa (1998) Relationship between plant and soil water status in five field-growing cotton (GossypiumhirsutumL) cultivars. Field Crops Res 57:29-48.

14. Loka, DA, DM Oosterhuis, GL Ritchie (2011) Stress Physiology in Cotton: Water-deficit stress in cotton The Cotton Foundation, Cordova, Tennessee (USA) p. 37-72.

15. Voltas, J, Lopez Corcoles H, Borras G (2005) Use of biplot analysis and factorial regression for the investigation of superior genotypes in multi environment trials. Eur Journal Agronomy 22(3): 309-324.

16. Cook CG (1985) Identifying root traits among MAR and non-MAR cotton, Gossypium hirsutum L cultivars that relate to performance under limited moisture conditions. Master Thesis Texas A\&M University, USA.

17. Pace PF, Cralle TH, SHM El-Halawany, Cothren JT, Senseman SA (1999) drought-induced changes in shoots and root growth of young cotton plants. The J Cotton Sci 3: 183-187.
18. Adil J, Shahid MN, Aftab B, Rashid B, Sarwar MB, et al. (2014) Water stress mediated changes in morphology and physiology of Gossypiumarboreum (Var FDH-786). J Plant Sci 2: 179-186.

19. Clarke JM, TM McCaig (1982) Evaluation of techniques for screening for drought resistance in wheat. Crop Sci 22: 1036-1040.

20. Radoglou KM, Jarvis PG (1990) Effects of $\mathrm{CO}_{2}$ enrichment on four poplar clones II Leaf surface properties. Annals of Botany 65(6): 627-632.

21. Iqbal K, FM Azhar, IA Khan, Ullah E (2010) Assessment of cotton (Gossypiumhirsutum L) germplasm under water stress condition. Int J Agric Biol 12: 251-255.

22. Soomro MH, Markhand GS, Soomro BA (2011) Screening Pakistani cotton for drought tolerance. Pak J Bot 44(1): 383-388.

23. ShahAR,Khan TM,Sadaqat HA,ChathaAA (2011) Alterations in leaf pigments in cotton (Gossypium hirsutum L)genotypes subjected to drought stress conditions. Int J Agric Biol 13: 902-908.

24. Briton GGD, Sofiatti V, Lima MMDV, Carvalho LPV (2011) Physiological traits for drought phenotyping in cotton Acta Scientiarum Agronomy 33(1): 117-125.

25. Cardenal LYR, Mora-Oberlaender J, Chaparro-Giraldo A (2013) Study of Gene Flow from Gm Cotton (Gossypium Hirsutum) Varieties In "El Espinal" (Tolima, Colombia). Acta biol Colomb 18(3): 489-498.

26. Comas LH, Becker SR, Cruz VMV, Byrne PF, Dierig DA (2013) Root traits contributing to plant productivity under drought. Front Plant Sci 4: 442.

27. LuoHH,Zhang YL, WF Zhang (2016) Effects of water stress and rewatering on photosynthesis, root activity, and yield of cotton with drip irrigation under mulch.Photosynthetica 54: 65-73.

28. Liu, G, X Li, S Jin, X Liu, L Zhu, Y, et al. (2014) Overexpression of rice NAC gene SNAC1improves drought and salt tolerance by enhancing root development and reducing transpiration rate in transgenic cotton PLoS ONE.

29. Bhatt JG, Andal R(1979) Variation in foliar anatomy of cotton. Proc Ind Acad Sci 88: 451-453.

30. Mvula J, James M, Bokosi VK, Banda MHP (2018) Screening cotton (Gossypium hirsutum L) genotypes for drought tolerance under screen house conditions in Malawi. J Plant Breed and Crop Sci 10(2): 48-57.

31. Peterson CA, Murrmann M, Steudle E (1993) Location of the major barriers to water and ion movement in young roots of Zea mays L. Planta 190: 127-113.

32. Basal, H, Smith CW, Thaxtonand PS, Hemphill JK (2004) Seedling drought tolerance in upland cotton American Society Agronomy 45: 766-771.

33. Imran M, S Kamaran, TM Khan, MA Muneer, MA Rashid, et al. (2016) Genetic analysis of fiber quality parameter under water stress in upland cotton (Gossypium hirsutumL). J Agri and Envi Sci 5(1): 134-139.

34. Levitt J (1980)Responces of plants to environment $2^{\text {nd }}$ Edition, Academic press, New York, USA.

35. Singh SB, Singh D (2004) Genetic analysis of morph-physiological parameters in cotton (Gossypium hirsutum L) Indian. J Genet Plant Breed 61: $57-60$.

36. Parida AK, Dagaonka VS, Phalak MS, Aurangabadkar LP (2008) Differential responses of the enzymes involved in proline biosynthesis and degradation in drought tolerant and sensitive cotton genotypes during drought stress and recovery. Acta Physiol Plant 30: 619-627.

37. Noreen S, Athar U, Ashraf M (2013) Interactive effects of watering regimes and exogenously applied osmoprotectants on earliness indices and leaf area index in cotton (Gossypium hirsutum L) crop Pakistan. Journal of Botany 45(6): 1873-1881. 
38. Franca MGC, ATP Thi, Pimental C, ROP Rossiello, YZ Fodil (2000) Differences growth and water relations among Phaseolus vulgaris cultivars in response to induced drought stress. Environ Exp Bot 43 227-237.

39. Sarwar M, Saleem MF, Ullah N (2017) Exogenously applied growth regulators protect the cotton crop from heat-induced injury by modulating plant defense mechanism. Sci Rep 8(17): 1-15.

40. Aboughadareh AP, Ahmadi J, Mehrabi AA, Etminan A, Moghaddam M, et al. (2017) Physiological responses to drought stress in wild relatives of wheat: implications for wheat improvement. Acta Physiol Plant 39: 106114.

41. Blum A (2009 Effective use of water (EUW) and not water-use efficiency (WUE) is the target of crop yield improvement under drought stress. Field Crops Res 112: 119-123.

42. Blum A (2011) Plant Breeding for Water-Limited EnvironmentsNew York, NY, Springer.

43. Barnabas B, Jager K, Feher A (2008) The effect of drought and heat stress on reproductive processes in cereals. Plant Cell Environ 31: 11-38.

44. Sinclair TR, Zwieniecki MA, Holbrook NM (2008) Low leaf hydraulic conductance associated with drought tolerance in soybean. Physiol Plant 132: 446-451.

ISSN: 2574-1241

DOI: $10.26717 /$ BJSTR.2020.29.004738

Wajid Ali Jatoi. Biomed J Sci \& Tech Res

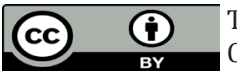

This work is licensed under Creative Commons Attribution 4.0 License

Submission Link: https://biomedres.us/submit-manuscript.php
45. Fang Y, Xiong L (2015) General mechanisms of drought response and their application in drought resistance improvement in plants. Cell Mol Life Sci 72: 673-689.

46. Wang CY, Isoda A, MS Li, DL Wang (2007) Growth and eco-physiological performance of cotton under water stress conditions. Agricultural Sciences in China 6(8): 949-955.

47. Jatoi WA, MJ Baloch, NU Khan, M Munir, AA Khakwani, et al. (2014) Heterosis for yield and physiological traits in wheat under water stress conditions. The J Animal and Plant Sci 24(1): 252-261.

48. Hetherington AM, Woodward FI (2003) The role of stomata in sensing and driving environmental change Nature 424: 901-908.

49. Iqbal, M, MA Khan, M Naeem, U Aziz, J Afzal, et al. (2013) Inducing drought tolerance in upland cotton (Gossypiumhirsutum L), accomplishments and future prospects. World Appl Sci J 21(7): 1062-1069.

50. Wang J, Griffiths R, Ying J, McCourt P, Huang Y (2009) Development of drought-tolerant (Brassica napus L) through genetic modulation of ABA mediated stomata responses. Crop Sci 49: 1539-1554.

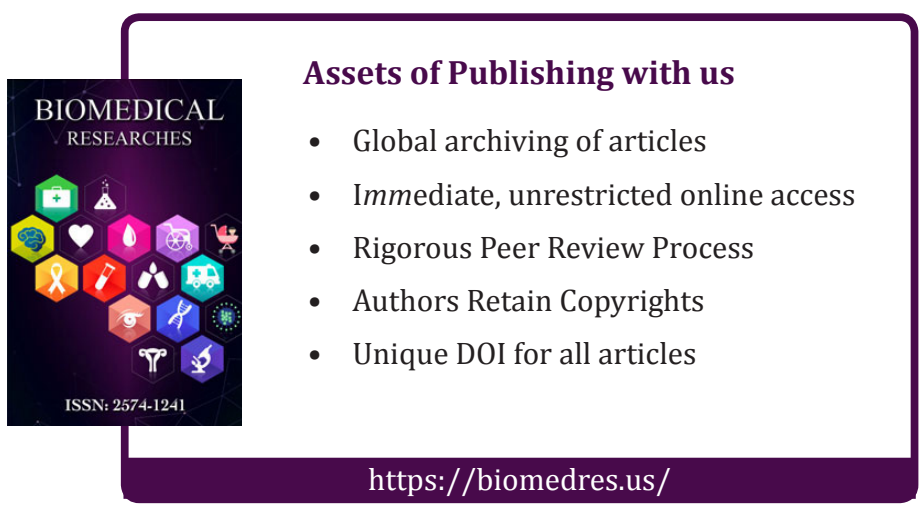

